From the effects of the parasitization all but one of the eggs were later found to be parasitized.

Later observations indicate that the attacks of this species are confined to the recently laid (unincubated) eggs of its hosts.

The parasitization records of this species now include Bruchus prosopis and Bruchus limbatus.

I have observed eggs of Bruchus sallaei and Bruchus prosopis concealed within pods parasitized by this species.

\title{
Descriptions of New Genera and Species of Hawaiian Encyrtidae (Hymenoptera), II.
}

BY P. H. TIMBERLAKE.

\section{ECTROMATINI.}

Anagyrus antoninae .n. sp. Figs. 1, 2.

A rather slender species belonging in the subgenus Epidinocarsis Girault but differing in the opaquely alutaceous sculpture and abundant white pubescence of the mesonotum.

Female: Head thinly subhemispherical, a little broader than long, thickest just above the anterior corners of the eyes; as seen from the side the curvature somewhat more abrupt next to the mouth and more gradual towards the occipital margin; as seen from in front the cheeks converge slightly towards the rather wide mouth. Occiput moderately concave with the margin rather acute above; frontovertex about one fourth longer again than its width at the ocelli, noticeably but not greatly widening anteriorly; ocelli placed in a right-angled triangle, the posterior pair about twice their own diameter from the eye-margins and three times their diameter from the occipital margin; eyes rather broadly oval, more bluntly rounded at the anterior end, strongly convex and slightly protuberant, just touching the occipital margin posteriorly: the outer margins nearly straight; face very slightly inflexed at a point opposite the lower third of the eyes, the scrobes rather deep, slightly converging but not meeting above, the facial prominence between the antennae somewhat arched below and visible in side view of head, the oral margin prominently emarginate at the middle, with the sinus rounded; cheeks short or about equal to two-thirds of the

Proc. Haw. Entom. Soc., IV, No. 2, June, 1920. 
eye width. Antennae inserted rather near together, close to the oral margin but nevertheless slightly more than half way to a line connecting the anterior corners of the eyes, the upper end of the sockets touching this line; scape very broadly expanded beneath and exciuding the radicle over one half as wide as long; pedicel slender and elongate, about equal to the second funicle joint; flagellum slender, cylindrical, slightly thicker distad; first funicle joint about four times longer than thick, the following joints gradually shortening, the last two joints equal and about twice as long as thick; club after collapsing slightly wider than the funicle and nearly as long as the three preceding joints combined, rather acutely pionted at apex, its first joint longest, the middle one shortest.

Thorax moderately robust, rather wide and strongly depressed;

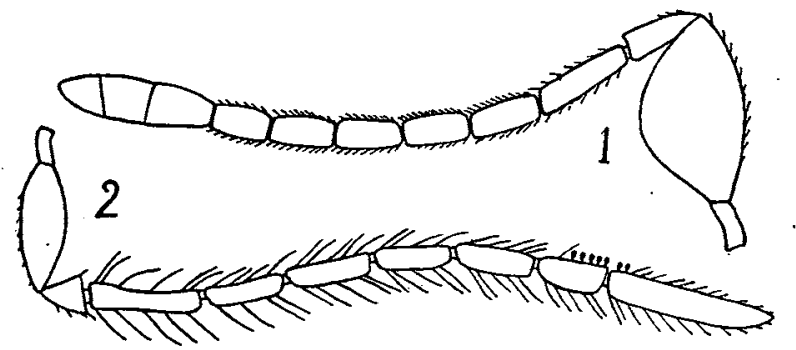

Figs. I and 2, Anagyrus antoninae, female and male antennae respectively.

pronotum strongly arcuate; mesoscutum nearly twice as wide as its median length, its posterior margin straight except for a rounded. median projection which overlaps the inner ends of the axillae; scutellum large, somewhat longer than wide and rather acute at apex. Abdomen about a fourth longer than the head and thorax combined, very narrowly triangular as seen from above, strongly compressed with the dorsum deeply sunken in after death; ovipositor shortly protruded, its sheaths compressed, broader towards the base and tapering towards the apex.

Wings reaching slightly beyond apex of abdomen, rather narrow; marginal vein about thrice as long as thick, nearly equal to the stigmal, the latter straight, slightly enlarged at apex with a short stout spur, postmarginal vein short and spurlike; discal ciliation moderately dense, nearly uniform to the base of the wing, the speculum broad, extending obliquely a little more than half way across the disk from the stigmal vein and with a very small cut-off portion below widely separated from the main part.

Head rather smooth and somewhat shiny, with extremely minute granular reticulations, the frons with rather numerous minute pinpunctures; mesonotum opaquely alutaceous; metanotum, propodeum, pleura and abdomen somewhat shiny, the pleura being very finely and 
delicately reticulate, the abdomen more distinctly -eticulate with the lines on the first tergite arranged more or less concentrically, more distinctly so towards the middle of the segment, the middle tergites smooth and polished, the last tergite more coarsely reticulate with longitudinal lines and appearing somewhat rugulose.

Eyes with a very fine, sparse pile; cheeks, lower part of face, anterior orbits of eyes, and the frons with moderately abundant whitish pubescence; oral margin with a fringe of much longer white hairs; mesoscutum, axillae and scutellum with a moderately dense, appressed white pubescence of short flattened hairs, the scutellum with a pair of rather long, black bristles at apex and a pair of shorter bristles placed just in front of the apical pair and more towards the sides; metapleura, first tergite and sides of abdomen with a few scattered, very fine, whitish hairs.

Length: (1.00 to) 1.87 ; width of vertex: 0.219 ; width of mesoscutum: 0.52 ; length of fore-wing: 1.37 ; width of fore-wing: $0.523 \mathrm{~mm}$.

Head black, the mandibles reddish brown; scape shining black with a broad, transparent white band just before the apex, base of pedicel black, the apical, two-thirds white, funicle blackish gradually becoming paler distad so that more or less of the sixth and sometimes part of the fifth joint becomes yellowish white like the club. Mesonotum dull ochraceous orange (R.), the anterior margin of the scutum blackish, or more rarely and apparently only in small specimens the whole scutum except laterally and the central part of the scutellum may be suffused with black; posterior margin of the propleura, anterior part of the mesopleura and the mesosternum nearly concolorous with mesoscutum; rest of the propleura and pronotum black; most of the mesopleura, the metanotum, propodeum and abdomen blackish, the metapleura and sometimes the base of the venter brown; prepectal plates and tegulae whitish. Legs maize yellow (R.), the coxae more whitish the tarsi deeper yellow with apex of the last joint blackish. Wings hyaline, the veins yellowish brown.

Male: Head much thinner fronto-occipitally than in the female, the curvature nearly uniform from oral to occipital margin, as seen from in front somewhat broader in proportion to the length, being widest above the middle of the eyes; the latter more protuberant and considerably smaller; frontovertex plainly wider than long, the ocelli in a slightly obtuse-angled triangle, the posterior pair about as far removed from either the eye or occipital margin as one half their distance apart; face and cheeks considerably longer than in the female, the scrobes in the form of rather short parallel furrows extending upward to the middle of the eyes and separated by the facial prominence, which is not arched and smaller than in the female so that it is hardly visible in side view of head. Antennae inserted close together just below the lins connecting the lower corners of the eyes and far removed from the oral margin; scape somewhat shorter than in the female, compressed but much less expanded beneath, being narrowly oval or about one 
third as wide as long excluding the radicle; pedicel short or hardly longer than its apical thickness; flagellum slender, cylindrical, clothed with long hairs more or less distinctly verticillate, each funicle joint angularly incised at apex; first funicle joint about five times as long as thick, the following joints gradually shortening, the sixth being somewhat more than one half as long as the first; first joint with five whorls of hairs, the following joints with three whorls, the hairs on the under surface excepting on most of the first joint one half shorter and semidecumbent; club long, slender, very pointed at apex, as long as the last two funicle joints and one-half of the fourth joint, provided with about seven whorls of hairs which become gradually shorter and more crowded towards the apex; under side of the sixth funicle joint with a row of five to seven short, erect, clavate hairs, the base of club with two more in alignment.

Thorax as in the female; abdomen much smaller, or about fourfifths as long as the thorax, being ovate, depressed, broadest just beyond the cordate base and truncate at apex. Wings somewhat shorter and proportionately much wider than in the female, the disk much less densely ciliated; the speculum broad, extending from the stigmal vein obliquely towards the opposite margin, briefly interrupted below the middle, the cut-off portion being large and distinct; marginal vein much shorter or about equal to one-half the stigmal, the postmarginal better developed or as long as the marginal.

Face, mesoscutum and axillae very minutely reticulate and moderately shiny, the frontovertex more opaque and microscopically, transversely lineolate with a few scattered minute punctures; scutellum granular reticulate and opaque but becoming smooth and shining on the lateral and posterior margins, pleura and abdomen a little more shiny and more coarsely reticulate than the mesoscutum, the lines on the first tergite concentrically arranged as in the female. Pubescence about as abundant as in the female but much less conspicuous, being whitish only on the face and cheeks and less distinctly whitish on the sides of the mesoscutum, the hairs on the mesonotum being longer and not flatiened; eyes more densely pubescent.

Length: ( $0.6 \mathrm{I}$ to) I.I6; width of vertex: 0.252 ; width of mesoscutum: 0.426 ; length of wing: I.II; width of fore-wing: $0.502 \mathrm{~mm}$.

Coloration black, moderately shining, the frontovertex and scutellum more or less opaque; mandibles brown; posterior margin of the propleura and the prepectal plates translucent yellowish; antennae bląck with the apex of the pedicel obscurely yellowish; legs maize yellow (R.), the hind coxae somewhat dusky at base; wings hyaline, the veins pale brownish.

Described from 94 females, 50 males (type, allotype and paratypes) reared from Antonina indica Green on Bermuda grass, Punahou district, Honolulu, Oahu, May 26 to July, 
1919 , and 1 male (paratype) reared from the same host, Kaimuki, Oahu, Feb. 2, 1919 (Timberlake). This is undoubtedly an immigrant species, and was presumably introduced with the host'years ago from some part of the Orient. It belongs to what appears to be a distinctly Oriental and Australian group of Anagyrus.

\section{Xanthoencyrtus Ashmead.}

Xanthoencyrtus Ashmead, Canad. Entom. vol. 34, p. 302, 1902.

Scelioencyrtus Girault, Mem. Queensland Museum, Vol 4, p. 161, 1915.

Mirastymachus Girault, Journ. N. Y. Entom.. Soc., vol. 23, p. 166, 1915 .

Before the descriptions of the four new species of Xanthoencyrtus published in Part I of this paper* had appeared in print, three more were discovered on Oahu and Maui mainly through the efforts of Mr. Bridwell. It is becoming evident, therefore, that probably only a small beginning has been made in elucidating our Hawaiian species, as there is no apparent reason why each island of the group should not be represented by one or more species. $U p$ to the present time they have found only on Laysan, Oahu and Mani, although the introduced species, fullawayi, occurs on Hawaii.

Our endemic species have been found chiefly if not entirely in the tussocks of Eragrostis variabilis, a coarse grass which grows in great profusion on the steep sides of the barren foothills, and less luxuriantly in similar rocky places within the native forests, as well as in regions at lower elevations that have much less rainfall. This grass is often infested with a species of mealybug, Trionymus insularis Ehrhorn, which serves as the host to these little parasites. Although apterus is the only species that has been actually reared, there seems to be no doubt that the others also parasitize this same mealybug

*Proc. Haw. Entom. Soc., vol. 4, No. I, pp. 20r-206, July, rgrg. 
with the possible exception of laysanensis and semiflavus, of whose habits we know the least at present. Not only do the different species have the same host but more remarkable still is the fact that two of these closely allied species have been found together, semiluteus and bridwelli thus occurring within a few rods of each other on the south wall of Palolo Valley. The effect of isolation, however, is shown in these species to a fine degree.

The introduced species, fullawayi, belongs to X'anthoencyrtus, sensu stricto, whereas apterus and allies fall in the subgenus, Mirastymachus Girault, which differs chiefly in having three club joints instead of two. With only a few species of the two groups known outside of Hawaii (there being one European, two American and three Australian species described) the value of this character is not fully established, although it may be found necessary to recognize Mirastymachus as a good genus later. The main distinguishing character, moreover, obtains only in the female sex.

The following descriptions have been made comparative only, on account of the close similarity of the species to apterus, to the full description of which reference should be made*. The depression on the dorsal surface of the head between the eyes noted in the previous paper proves to be due to shrinkage, as this space is slightly convex in living or fresh material. Since the head in each species shrinks a little differently from other species and somewhat uniformly this character may have some value, although it is by no means absolute. Occasionally a specimen of large size will be found which remains unshrunken as is the case in the type of semiflavus and in one specimen of apterus from Kahihi, Oahu.

The following synoptic tables to the endemic species have been prepared to show their relationship to each other and to facilitate their identification.

\footnotetext{
*Proc. Haw. Entom. Soc., vol. 4, No. I, p. 201
} 
FEMALES.

i. Abdomen piceous or black

Abdomen orange-yellow or reddish.

Head, thorax and abdomen reddish orange, the under side of thorax and the legs paler yellow, antennae at base nearly concolorous with head but passing into piceous on the third or fourth funicle

. joint; head and body opaquely alutaceous; the pubescence whitish and comparatively conspicuous._-_-_-_-_sanguineus $\mathrm{n}$. $\mathrm{sp}$.

Head and thorax pale yellow, the abdomen reddish orange, legs pale yellowish white, antennae at base concolorous with head, the funicle dusky and passing into blackish on the club; head and body very finely reticulate and somewhat shiny; the pubescence very fine and sparse and not easily seen._-_._-_semiluteus $\mathrm{n}$. sp.

2. Head but slightly or not at all wider than long, the space between the eyes from antennal sockets to occipital margin about one-fifth longer than wide

Head distinctly wider than long, the space between the eyes only one-tenth longer than wide (appearing to the eye a little wider than long.

Head and thorax ochraceous orange, antennae and legs concolorous, the club and abdomen piceous; head and body smooth and shiny, without reticulations; the pubescence dusky and rather sparse. semiflavus Timb.

3. Legs entirely yellowish or ochraceous, the funicle piceous or black with the first joint only sometimes yellowish_.............. Hind femora piceous, the funicle entirely ochraceons.

Head, antennae except club, thorax and legs except hind femora ochraceous orange, club and abdomen piceous or black; head and body smooth and strongly shiny; the pubescence very sparse and not easily detected; head slightly broader than long_bridzelli n. sp.

4. Head circular in outline, the ocelli absent.

Head, thorax, basal tergite of abdomen, legs, scape and pedicel ochraceous orange, the remainder of antennae and abdomen piceous or black; head and body smooth, without reticulations and strongly shiny; pubescence sparse and inconspicuous_--_laysanensis Timb.

Head slightly, wider than long, and somewhat truncate at oral and occipital margins, the ocelli present.

Head, thorax and more or less of basal tergite of abdomen ochraceous orange, the scape and pedicel concolorous, the under side of thorax and the legs a little paler, abdomen and flagellum piceous or blackish, the first funicle joint paler or even yellowish; head and body smooth and very shiny, the mesoscutum and sometimes the head with fine reticulations; pubescence dark

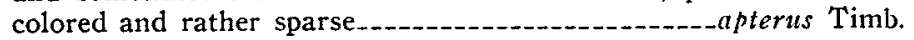


I. Abdomen piceous or black

Abdomen orange-yellow or reddish

. Body more or less smooth and shiny with fine reticulations; pubescence pale, sparse and not at all conspicuous

Head and body opaquely alutaceous; pubescence whitish and comparatively prominent.

Head and thorax flame scarlet, the abdomen slightly redder, the underparts of thorax and the legs paler and yellower, scape and pedicel concolorous with head, the funicle and club piceous; sixth funicle joint and base of club with a row of about eight or nine

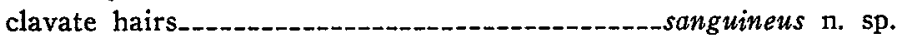

3. Head finely shagreened and nearly opaque, thorax and abdomen smooth and moderately shiny, the mesoscutum very finely reticulate, the basal tergite of abdomen somewhat more coarsely reticulate; coloration nearly uniformly capucine yellow, the legs paler yellow, the funicle and club black; sixth funicle joint and base of club with a row of about seven clavate hairs_-_-_-semiluteus n. sp.

Head and thorax finely reticulate and shiny, the basal tergite of abdomen somewhat more coarsely reticulate; coloration about orange rufous to flame scarlet with the abdomen redder, the legs paler and more yellowish, with the funicle and club black; sixth funicle joint and base of club with a row of about six clavate hairs.

apterus Timb.

4. Head and thorax finely, delicately reticulate; ocelli distinct; mesonotum perfectly flat to apex of scutellum; head, thorax, legs, scape and pedicel about xanthine orange, the remainder of the antennae and the abdomen piceous or black; sixth funicle joint and base of club with a row of about eight clavate hairs.

bridzelli n. sp.

Head and thorax smooth and shiny, without reticulations; ocelli very minute; head, thorax, legs, scape and pedicel about capucine yellow, the funicle and club piceous, the abdomen shining black; sixth funicle joint and base of club with a row of about seven clavate hairs -laysanensis Timb.

Xanthoencyrtus sanguineus $n$ sp. Fig. 9.

Female: In comparison with apterus this species differs as follows: Head practically of the same shape, the space between the eyes with about the same proportions and caving in after death very nearly the same, although the triangular raised area in the ocellar region is less prominent or even absent; ocelli practically the same in size, the posterior pair a little closer together than the distance from either to the eye-margin. Antennae longer, the scape much narrower or not over a sixth as wide as long; pedicel about the same, being distinctly 
wider at apex than the following joint; the funicle joints all longer than thick, the first nearly twice as long as thick, the sixth about a third longer than thick; club longer but keeping the same proportion to the preceding joints, and the relative proportion of its own joints to each other practically the same. Thorax nearly as in apterus, the posterior margin of pronotum gently or deeply, irregularly arcuate, the degree depending apparently on shrinkage, the mesoscutum consequently appearing either transverse or triangularly prolonged medially; scutellum not broadly rounded at apex but rather acute; abdomen shorter or not much longer than the head and thorax combined when the former is stretched forward; ovipositor distinctly although shortly protruded. Sculpture differing remarkably, the head, dorsal surface of the thorax and the abdomen being extremely finely reticulate and producing an opaquely alutaceous effect or not at all shiny as in apterus. The whitish pubescence is also much more abundant and conspicuous than in apterus and other Hawaiian species, although by no means so conspicuous as in species of Aphycus, Blastothrix or some species of Anagyrus.

Length: ( 0.78 to) I.29 (with head stretched forward); width of vertex: $0.2 \mathrm{I} 4$; width of mesoscutum: $0.285 \mathrm{~mm}$.

Coloration nearly uniformly bittersweet orange (R.), the under side of the thorax and the legs considerably paler and yellowish, the scape and pedicel nearly concolorous but a little browner, the basal two or three joints of funicle usually dusky yellowish or more rarely dilute piceous, the remainder of funicle and the club piceous or black.

Male: Similar to the male of apterus but the scape is much narrow$\mathrm{er}$, the last funicle joint and base of club with a row of about eight or sometimes nine clavate hairs; thorax differing as in the female, the abdomen ovate and a little shorter than the thorax. Sculpture as in the female except that the apical half of the first tergite of the abdomen and the intermediate tergites have close set, microscopic lineolations longitudinally arranged, thus producing an effect as if covered with extremely minute, glistening scales. Pubescence a little more prominent than in the female.

Length: ( 0.50 to) 0.89 ; width of vertex: 0.216 ; width of mesoscutum: $0.299 \mathrm{~mm}$.

Coloration about flame scarlet (R.), or slightly darker, the abdomen a little redder, the lineolate area appearing golden yellow in most aspects, the underparts of the thorax and the legs a little paler and yellower; scape and pedicel concolorous with the head, the funicle and the club piceous.

Described from 20 females, 41 males (type, allotype and paratypes) collected on Eragrostis variabilis on the north wall of Iao Valley, Maui, about one-half mile from the Needle, Jily 6, 1919 (Timberlake). 

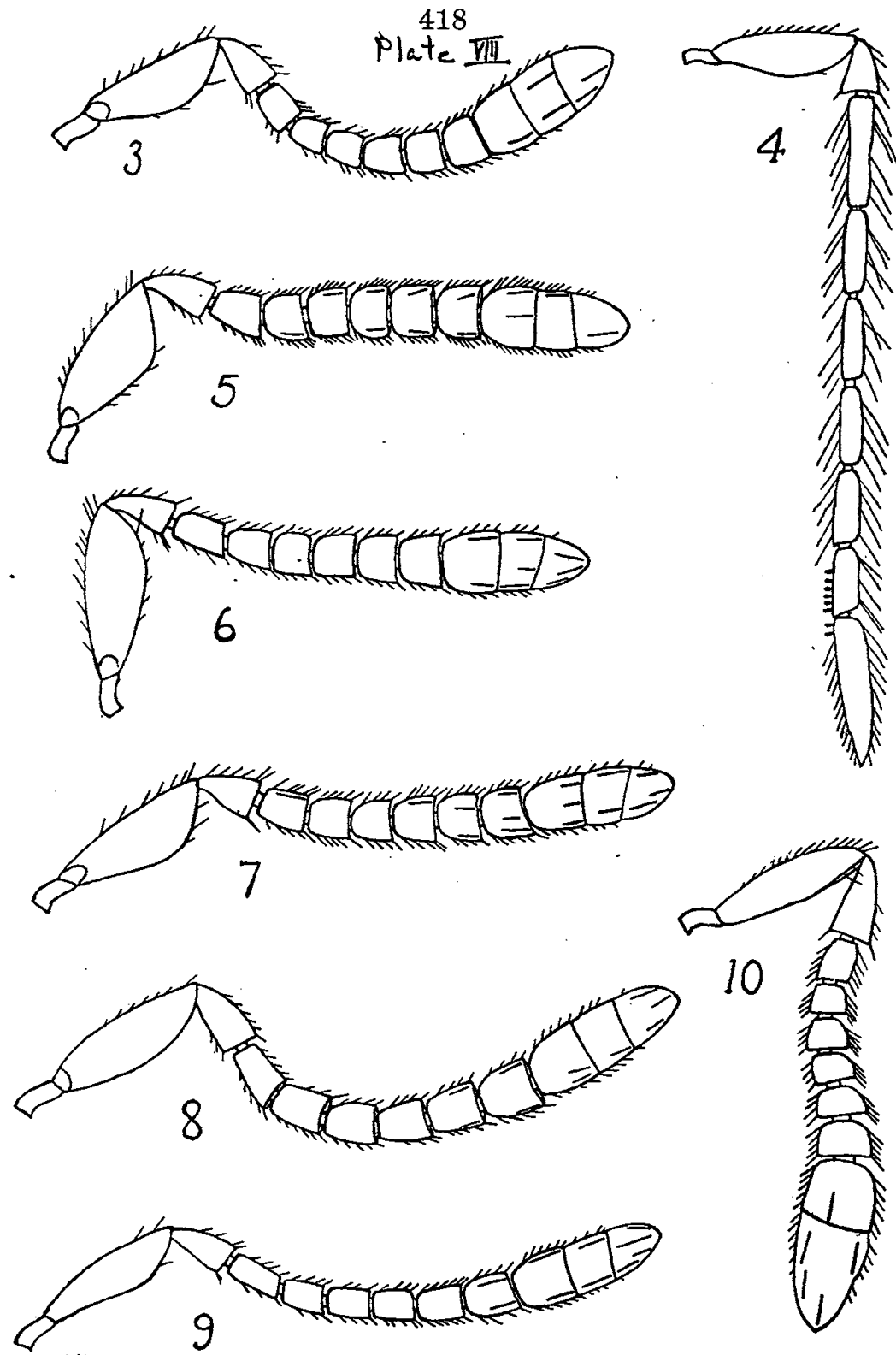

Figs. 3 and 4 , Xanthoencyrtus apterus, female and male antenna.

Fig. 5, Xanthoencyrtus laysanensis, female antenna.

Fig. 6, Xanthoencyrtus semiflavus, female antenna.

Fig. 7, Xanthoensyrtus bridwelli, female antenna.

Fig. 8, Xanthoencyrtus semilutens, female antenna.

Fig. 9, Xanthoencyrtus sanguineus, female antenna.

Fig. Io, Xanthoencyrtus fullazvayi, female antenna. 
Xanthoencyrtus semiluteus n. sp. Fig. 8.

Female: From apterus differing structurally as follows: Head nearly of the same shape but the eyes considerably smaller so that the space between them from the antennal sockets to the occipital margin is only one-tenth longer than wide (by micrometer measurement), appearing to the eye a little wider than long, and therefore practically as in semiflavus although the space is sunken in after death as in apterus; ocelli rather more minute, although more prominent by their contrast in coloration with background, the posterior pair considerably more remote from the eye-margins than their distance apart; antennae nearly as in sanguineus. Thorax nearly as in apterus, the posterior margin of pronotum more gently arcuate, the mesoscutum more transverse and somewhat over twice as wide as its median length, the scutellum broadly rounded at apex. Abdomen conspicuously large, over twice as long as head and thorax combined or rather larger and longer than in apterus, the ovipositor shortly protruded. Head, thoracic notum and basal tergite of abdomen very minutely reticulate, the surface considerably more shiny than in sanguineus but much less so than in apterus. Pubescence very fine and sparse on head and thorax and not easily detected.

Length: I.I7 (with head nearly vertical); width of vertex: 0.216 ; width of mesoscutum: $0.278 \mathrm{~mm}$.

Head and base of antennae buff yellow (R.), the antennae gradually shading into piceous beginning at the middle of the funicle; thorax maize yellow (R.), the underparts paler, the mesopleura especially being yellowish white; legs nearly maize yellow but paler at base; abdomen about salmon orange (R.).

Male: Structuraly much like the male of apterus but the eyes are a little smaller, with the space between wider, the posterior pair of ocelli a little more remote from the eye-margin than their distance apart; -scape of antennae narrower, the sixth funicle joint with a row of about five clavate hairs and the base of the club with two or three more; thcrax differing as in the female; abdomen ovate, as long as the thorax. Head very finely shagreened and opaque, the thorax sculptured as in the female, the basal tergite of abdomen more coarsely reticulate than in the female, although somewhat more finely than in apterus; thorax and abdomen both much less shiny. Pubescence much more abundant than in the female, but not contrasting in color with the body, and rather more abundant than in the male of apterus, although less easily seen.

Length: ( 0.68 to) 0.865 ; width of vertex: 0.214 ; width of mesoscutum : $0.285 \mathrm{~mm}$.

- Coloration nearly uniformly capucine yellow (R.), the scape and pedicel about concolorous, the funicle and club black, the legs paler or about light orange yellow (R.) ; in two of the paratypes the coloration is much redder but apparently due to discoloration. 
Described from 1 female. 3 males (type, allotype and paratypes) collected on Eragrostis variabilis on the south wall of Palolo Valley, Oahu, May 30, 1919 (J. C. Bridwell) and 1 male (paratype) on the same grass on the side of the southernmost ridge of the Koolau Range, Oahu, Nov. 16, 1919 (Bridwell).

\section{Xanthoencyrtus bridwelli n. sp. Fig. 7.}

Female: Head slightly wider than in apterus in proportion to the length, the space between the eyes a little wider, the ocelli more minute and indistinct, the space separating the posterior pair from the eyemargins distinctly greater than their distance apart; the space between the eyes caved in after death much as in apterus but the triangular raised area in the upper part much less prominent and forming anteriorly a right angle instead of an acute angle. Antennae a little stouter, the scape a trifle wider, the funicle stouter so that the pedicel at apex is hardly thicker than the following joint, the first funicle joint somewhat longer and the sixth somewhat wider, the latter being a little wider than long. Thorax practically as in apterus, the abdomen apparently somewhat smaller, the ovipositor slightly protruded. Head, thorax and abdomen very smooth and shiny, with no reticulations apparent in any part. Pubescence very sparse and not easily detected.

Length: ( 0.79 to) I.32 (with head stretched forward); width of vertex : 0.235 ; width of mesoscutum: $0.273 \mathrm{~mm}$.

Head and thorax ochraceous orange (R.), the scape and pedicel concolorous, the funicle ochraceous buff (R.), the club piceous and often paler or yellowish at base; legs slightly paler than the body, the hind coxae and femorexcept at apex and sometimes the middle coxae more or less piceous; abdomen shining black.

Male: Much like the male of apterus but the head is wider with the space between the eyes much broader, the ocelli more minute and closer together so that the distance from either of the posterior pair tothe eye-margin is considerably greater than their distance apart; scape practically the same, the sixth funicle joint and base of club with a. row of about eight clavate hairs arranged five and three on each respectively; thorax similar, the scutellum flat from base to apex; abdomen triangularly to broadly ovate, depending much on manner of drying after death, as long or a little longer than thorax. Head and notum of thorax extremely finely and delicately reticulate, appearing smooth and shiny; basal tergite of abdomen much more distinctly and coarsely reticulate than on the head or thorax, and slightly more finely and more uniformly as to size than in apterus. Pubescence very sparse and fine.

Length: ( 0.55 to) 0.88 ; width of vertex: 0.216 ; width of mesoscutum: $0.254 \mathrm{~mm}$. 
Coloration of head, thorax, scape and pedicel about xanthine orange (R.), the legs concolorous with the front coxae and all the tarsi paler; flagellum of the antennae and the abdomen piceous or black.

Described from 15 females, 12 males (type, allotype and paratypes) collected on Eragrostis variabilis on the south wall of Palolo Valley, Oahu, May 30, 1919 (J. C. Bridwell), and 1 female, 1 male (paratypes) on the same grass at Koko Head, Oahu, 25 ft. elevation, Dec. 15, 1918 (Giffard and Muir). Xanthoencyrtus apterus Timb. Figs. 3, 4.

Xanthoencyrtus apterus Timberlake. Proc. Haw. Entom. Soc., vol. 4, p. 201, July, 1919.

The following additional material of this species has been collected: 23 females, 46 males on Eragrostis variabilis, ridge west of Kalihi Valley (about $1000 \mathrm{ft}$.), Oahu, June 15, 1919 (Bridwell and Timberlake), nearly one-half of the specimens having been reared from the mealybug, Trionymus insularis Ehrhorn, June 17-30, one to three issuing from a host; and 4 females, 11 males on Eragrostis variabilis, Manoa Ridge, Oahu, June 1, 1919 (J. C. Bridwell).

The Kalihi specimens are nearly identical with the types from Nuuanu Pali, but the coloration of the females is somewhat paler and without the trace of tawny which may have been due to discoloration in the types. In both series the color is more ochraceous orange (R.) than yellow ocher. The first funicle joint varies considerably in the amount of yellowish coloration and in one female is entirely black; the base of the abdomen is likewise variable, some specimens having the first tergite entirely pale but in one female it is entirely black. In the males the coloration is about orange rufous to flame scarlet (R.).

The Manoa specimens are distinguished by a fine reticulation on the head of the female and by a considerably greater number of darkcolored, minute, bristle-like hairs on the mesoscutum, but the coloration is practically as in the Kalihi specimens.

In the original description, p. 202, line 4 , the following correction should be made, for "the latter" read "occipital margin." The ovipositor in this and probably in all the Hawaiian species is hidden in repose, but in most mounted specimens the abdomen is more os less distorted, somewhat in the manner assumed during oviposition so that the ovipositor and sheaths are shortly protruded. The latter are flat and laminate, broader at base and tapering to a blunt point. The abdomen of the male usually remains oval-shaped after drying or not flattening out wider than the thorax and becoming rotund as in the allotype specimen. 


\section{MIRINI.}

Coelopencyrtus orbi n. sp. Figs. 11-13.

Female: Similar to Coelopencyrtus odyneri but the head is distinctly wider than long, instead of nearly as long as wide, the face and cheeks shorter, the oral margin of face hardly produced medially; frontovertex wider or about twice as long as wide, slightly widening behind the ocelli but hardly at all anteriorly, the ocelli in an equilateral triangle, the posterior pair not more than their own diameter from the occipital margin. Antennae a little shorter and stouter,- the pubescence more prominent and bristle-like, the scape distinctly wider, the funicle joints more transverse but keeping practically the same relative proportion to each other. Sculpture of the same type, although somewhat coarser, especially on the frontovertex and scutellum, the pin-punctures of the frontovertex more prominent. Pubescence much sparser, the eyes bare, the mesonotal bristles not more than one--half as numerous, there being about sixteen along the anterior margin of the mesoscutum and ten along the posterior margin.

Length: ( 1.00 to) $\mathrm{r.38}$; width of vertex at ocelli: 0.164 ; width of mesoscutum: 0.473 ; length of fore-wing: I.I3; width of fore-wing: $0.490 \mathrm{~mm}$.

Coloration much as in odyneri but the mesoscutum does not have the brassy reflections, the scutellum is more metallic with a dark purplish luster, more greenish toward the sides; legs almost entirely black, but the middle tibial spur is yellowish and the tarsi are more or less yellowish or yellowish brown beneath and varying from brown to fuscous above but always blackish at apex of the last joint. Wings more deeply stained, being darker on the basal half and with a distinct fuscous streak at the base along the posterior margin.

Male: Head with the same remarkable structure as in odyneri but thinner fronto-occipitally, being only twice as thick above as at the oral margin, and as seen from in front it is no longer than wide and more nearly circular; frontovertex no longer than wide, the frons less protuberant and projecting less in front of the eyes; ocelli in a rightangled triangle, the anterior ocellus just reaching to a line drawn across the anterior margin of the eyes, the posterior pair hardly more than their own diameter from the occipital margin. Scape (Figs. I2, 13) as wide as in odyneri but more nearly like swezeyi in shape, the upper margin being curved arcuately inward, the lower margin evenly and strongly convex; pedicel with a large conical projection at base on the upper side, otherwise about a third longer again than thick; first funicle joint as wide as long, narrowed somewhat towards the base but not remarkably modified as in odyneri or swezeyi, following funicle joints all transverse, about equally long and increasing slightly in width distad; club as long as the last three funicle joints combined, considerably wider than the funicle and not strongly inclined as in odyneri. 

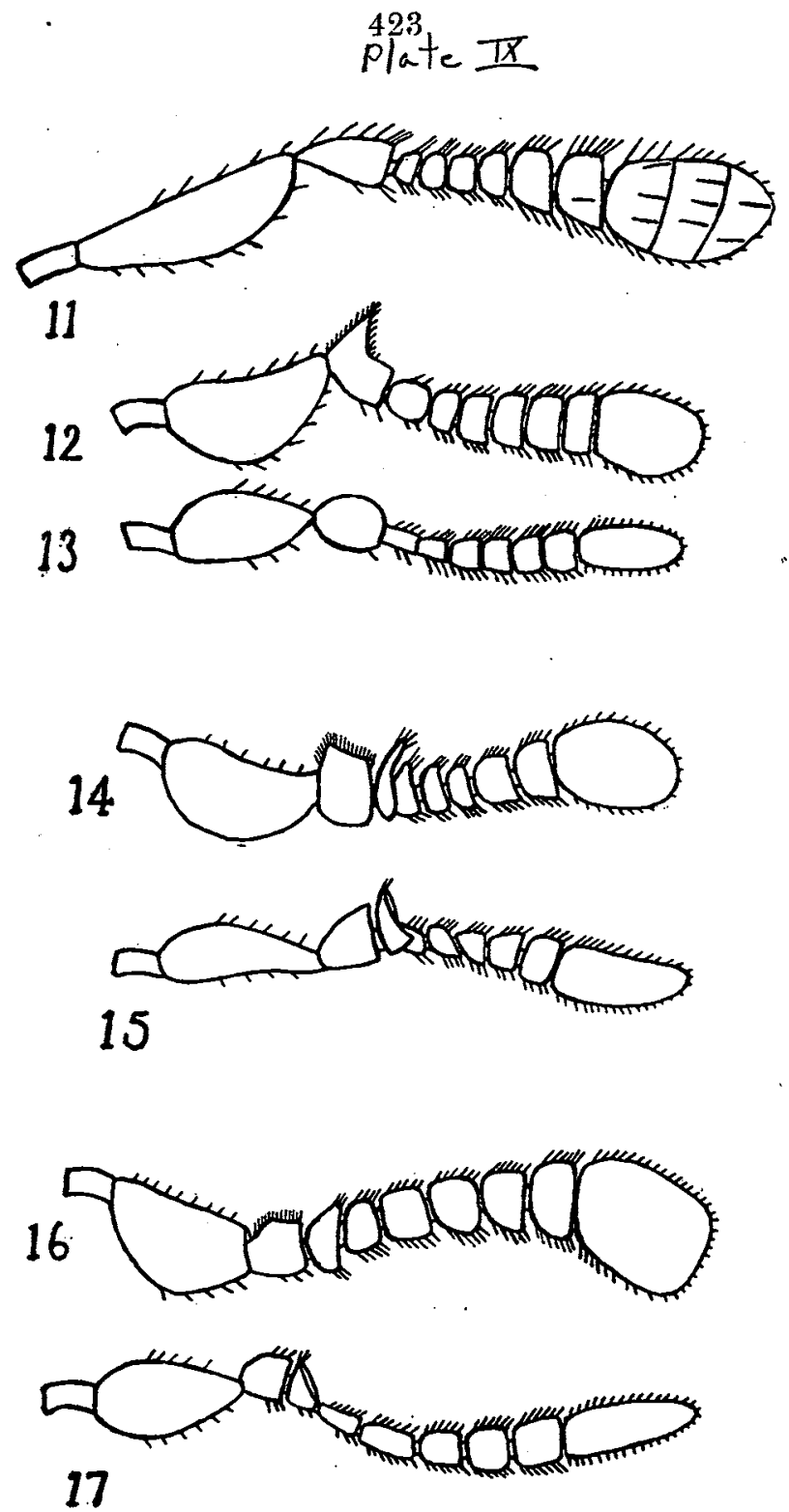

Fig. I1, Coelopencyrtus orbi, female antenna.

Figs. I2 and 13 , Coclopencyrtus orbi, two aspects of male antenna.

Figs. I4 and I5, Coelopencyrtus szezeyi, two aspects of male antenna.

Figs. 16 and 17 , Coelopencyrtus odyneri, two aspects of male antenna. 
Lower part of face above antennae with a median carina which widens out above and dissipates a little above the level of the lower corners of the eyes, the subquadrate, shallow, scrobal depression on either side of this. carina, limited outwardly at the corners by the antennal socket and margin of the eye, with a smooth and shining surface, and shows no trace of the dense shagreening present in odyneri or szeezeyi except to a comparatively very slight extent around its outer and upper margin; upper part of the face above the scrobes much more shagreened than in odyneri and less shiny, the surface being distinctly and finely reticulate, and with numerous minute setiferous punctures practically as in odyneri, although less prominent; frontovertex more distinctly shagreened, with the lines arranged fingerprint-like between and behind the ocelli; the setiferous punctures somewhat more prominent and mostly confined to the frons; sculpture otherwise as in the female.

The suberect pubescence on the frontovertex and upper part of face somewhat thinner than in odyneri, the tuft of fine pubescence on the pedicel confined to the conical projection, the funicle joints with coarser hair; eyes with very sparse, short, erect hairs; pubescence on other parts of the body differing from odyneri as described for the female.

Length: ( 1.08 to) 1.23 ; width of vertex at posterior ocelli: 0.216 ; width of mesoscutum: 0.443 length of fore-wing: 1.03 ; width of forewing: $0.483 \mathrm{~mm}$.

Coloration as in the female except that the antennae are slightly more brownish.

Described from 213 females, 9 males (type, allotype and paratypes) reared from two larvae of Odynerus orbus Perkins, Kipuka Puaulu, Kilauea, Hawaii, Nov. 21 and Nov. 28-29, 1919 (F. X. Williams), and 2 females (paratypes) found alive in a sealed cell of this Odynerus at the same locality, Nov. 1, 1919 (Williams). From the first larva there issued 2 s $\delta, 124 \& q$, and from the second 6 is $t$, $104 \% \&$, this brood being incomplete as about 35 pupae were killed by Acari.

\section{Xesmatia n. g.}

Closely related to Ooencyrtus Ashmead and differs in the female sex as follows: Head of the same shape and structure, although slightly thinner fronto-occipitally, antennae similar but the club somewhat larger; mandibles differing considerably in having three teeth, none very acute, the middle one much the largest, the upper and lower teeth both rather obscure, giving the appearance of a broad apex with a single median 
tooth (in Ooencyrtus the mandible has an acute ventral tooth and a broadly truncate inner one); palpi.practically the same, the maxillary pair with four short, nearly equal joints, the labial pair with two subequal, short joints.

Thorax similar, the axillae well separated at their tips as in Ooencyrtus; the scutellum a little larger and broader with the apex more rounded. Wings nearly the same, the marginal vein punctiform, the stigmal somewhat shorter than in Oocncyrtus and triangularly enlarged from base to apex with a short spur at apex projecting towards the costal margin; discal and marginal ciliation similar, the speculum however, greatly widening below. Legs similar, the middle tarsi slenderer and less strongly tapering towards the apex; the middle tibial spur slender and as long as the first tarsal joint.

Abdomen considerably smaller, after drying no longer than half the thorax and as wide, being much broader than long and well rounded at apex; the dorsum beyond the first tergite caving in after death in a peculiar manner, the venter, however, not compressed but broadly rounded from side to side in the form of nearly a semicircle near the base of abdomen; vibrissal plates situated on either side of the dorsum about half way between the base and apex and withdrawn within the dorsal concavity, the vibrissae consequently difficult to trace but reaching to the apex.

In sculpture differing appreciably, the surface of all parts of the head and body much smoother and shinier, for although fine, delicate reticulations occur on the head and mesoscutum, they do not produce a shagreened appearance as in Ooencyrtus, the scutellum, moreover, entirely smooth and polished; pubescence of the same character as in Ooencyrtus.

Genotype: Xesmatia flavipes n. sp.

Xesmatia flavipes n. sp. Figs. 18, 19.

Female: Head moderately thin fronto-occipitally, somewhat broader than long, being thickest and widest across the middle of the eyes, the dorsal surface well rounded from side to side; frontovertex occupying about one-third of the width of the head in dorsal view, about a third longer again than wide and becoming somewhat wider behind the ocelli; the latter in a right-angled triangle, the posterior pair somewhat less than one-half their own diameter from the eye-margins and about twice as far removed from the occipital margin; eyes very broadly oval or but little longer than wide, the inferio-posterior margin much less curved than the inner margins; cheeks somewhat shorter than the width of the eyes and rather strongly curved in towards the mouth as seen from in front; face nearly as wide as long, the scrobes in the form of a moderately deep, broadly ovate depression covering its larger part, reaching upward between the eyes to the anterior limit of the frons, and divided by a rather wide longitudinal ridge which runs about twothirds of the length of the depression from the antennal sockets up- 
ward. Antennae inserted rather close to the oral margin and well separated by the facial ridge, the distance between the sockets being about one-fourth less than the width of the frons; scape compressed linear, slightly widened at the middle and excluding the radicle about four times longer than wide; pedicel thicker at apex than the basal funicle joints and nearly as long as the first three of these combined; funicle increasing gradually in width distad, the first four joints subequal in size, the first being slightly longer than thick, the fourth slightly thicker than long, last two funicle joints larger and subquadrate; club large, oval, practically as long as the entire funicle and twice as wide as the preceding joint, its first joint distinctly longer than either of the following two.

Thorax strongly convex above, yet somewhat wider than its depth; pronotum strongly arcuate, the visible part very short; mesoscutum more than twice as wide as long, its basal margin slightly produced

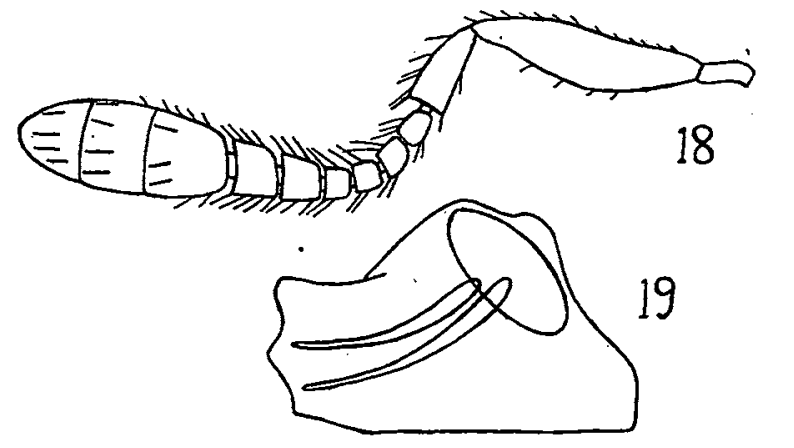

Figs. 18 and I9, Xesmatia flavipes, female antenna and mandible.

medially in a broad curve between the tips of the axillae; the latter rather small, distinetly separated medially and about twice as wide as long; scutellum large, strongly convex throughout, the apex well rounded, the lateral margins but little elevated and hardly declivous; propodeum very short medially, but triangularly enlarging at the sides, the metapleura small. Wings reaching far beyond the apex of abdomen and about normal in width; the disk finely, closely ciliated, the area below the submarginal vein with coarser, longer cilia arranged in about five oblique, transverse rows and with a sixth row parallel and close to the vein; marginal vein falling somewhat short of the middle of the disk; speculum not quite reaching to the stigmal vein, greatly and triangularly. widening below, and above on the distal side where it becomes suddenly narrowed with parallel sides it is guarded by a row of five cilia, which are hardly longer than others of the disk but much thickened at base; submarginal vein set with about twelve moderately long, slender bristles.

Cheeks and mesopleura with microscopic reticulations faintly im- 
pressed; prepectal plates and sides of the scrobal impression of the face more evidently and somewhat more coarsely reticulate; mesoscutum and base of the scutellum more faintly and minutely reticulate; facial ridge and most of the scutellum almost perfectly smooth and highly polished; frontovertex smoothish and with a few scattered minute pinpunctures; abdomen smooth and shiny, apparently without reticulations; the reticulations of all parts of the body are so faint that the general effect is of a smooth and polished surface except possibly on the sides of the scrobal impression and on the prepectal plates. Pubescence consisting of fine, brownish colored hairs of moderate length, rather sparse on the cheeks and frontovertex and moderately abundant on the mesoscutum; scutellum with only about a dozen such hairs on the basal half and two longer, more bristle-like hairs at apex; abdomen sparsely pubescent along the lateral and apical margins; pile of the eyes rather sparse and short; antennae with the usual vestiture of bristle-like hairs, most abundant on the pedicel and funicle, the club with considerably shorter, more erect hairs, which are abundant even to the apex.

Length: (0.74 to) 0.75 ; width of vertex at posterior ocelli: 0.143 ; width of mesoscutum: 0.398 ; length of fore-wing: 0.938 ; width of fore-wing: $0.43 \mathrm{I} \mathrm{mm}$.

General coloration metallic bluish black, the cheeks with a greenish luster, the frontovertex with a comparatively dull, bluish luster; mesoscutum with a strong blue and scutellum with a refulgent bluish green luster; pleura nearly pure black; luster of abdomen slightly greenish and partly iridescent especially on the basal tergite. Scape yellow ocher (R.), the flagellum yellowish brown, the upper side of pedicel and the club darker brown (the rest of the pedicel and the funicle when mounted in balsam appearing nearly as yellowish as the scape). Front legs nearly fuscous, yellowish only at the knees and apex of the tibia, the tarsi brown; middle and hind legs mostly yellow ocher (R.), but somewhat brownish along the upper margin of the femora and near the base of the tibiae on the upper side, the last joint of the tarsi brown. Wings hyaline, faintly tinged with brownish around the stigmal vein and along the posterior margin at the base; the veins brownish yellow.

Male: Not known.

Described from one female (type) collected on or near the rim of Palolo Crater, Oahu, Dec. 20, 1918 (J. C. Bridwell) and one female (paratype) collected at the head of Waianae Valley, Oahu, about $2400 \mathrm{ft}$. elevation, June 1, 1919 (Timberlake).

This species may possibly be endemic, but we can have no positive evidence on this point until the species is reared. 
On account of its small size and close relationship to Ooencyrtus it may prove to be an egg-parasite.

Plagiomerus hospes n. sp. Figs. 20, 21.

Female: Head considerably wider than long, the face abruptly inflexed from the horizontal frons, moderately thick above but becoming much thinner toward the mouth; occiput but slightly concave, the margin above rather acute; dorsal surface of head strongly convex; eyes mostly dorsal but the anterior margin reflexed on to the plane of the face rather more widely than in Plagiomerus diaspidis Crawford*, also larger than in that species, and in the form of a nearly equilateral triangle with the inner margins straighter and parallel; frontovertex comparatively narrow, apparently somewhat over twice as long as wide, the ocelli in a right-angled triangle with the posterior pair practically touching the eye-margins and rather remote from the occipital margin; cheeks about equal to the length of the eyes and arcuately converging towards the mouth; face broad, the scrobes in the form of a triangular, rather deep depression, reaching upward between the eyes to the anterior margin of the frons, separated on either side from the eye-margins by a convex rather wide space and divided on the lower three-fourths of its length by a rounded, triangularly shaped ridge broadest between

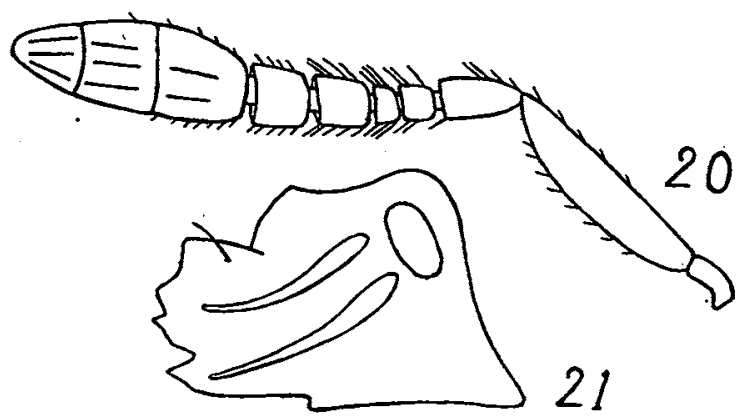

Figs. 20 and 21, Plagiomerus hospes, female antenna and mandible.

and somewhat below the antennal sockets. Antennae inserted slightly less than half way from the oral margin to a line connecting the lower corners of the eyes, the sockets widely separated by the facial ridge, their distance apart a little less than the distance from either to the nearest point of the corresponding eye; scape rather long and reaching slightly beyond the plane of the frons, compressed but linear, the lower margin somewhat convex; pedicel a little wider at apex than the following

*The head in all available specimens is much shrunken so that this difference may be illusory. 
joint, and somewhat longer than the first two funicle joints combined; funicle moderately increasing in thickness distad, the first joint about as wide as long, the second shorter and transverse, the last two much larger, the third being as wide as long and the fourth slightly transverse; club large, elongate oval and pointed at apex, considerably wider than the funicle and almost as long as the pedicel and funicle combined, its first joint the longest and the apical one a little the shortest. Mandibles with a short sharp spine on the ventral margin, the apical margin not greatly narrower than the base, with an acute ventral tooth rather deeply divided from the remaining edge, which is obliquely inclined and divided into three short rather acute teeth. Palpi short and transparent white; the maxillary pair four-jointed, with the apical joint considerably the longest, the middle joints subequal and about as long as wide, the basal joint about two-thirds as long as the apical; labial pair short, wide at the middle and tapering to either end, the basal joint slightly longer than the second.

Thorax strongly depressed and not very deep, about a fourth longer than wide; pronotum strongly arcuate; mesoscutum nearly twice as wide as long, its posterior margin slightly angulate at the middle; axillae fully twice as wide as long, being narrowly transverse and meetlng at their tips; scutellum a little wider across the base than its length, the apex forming an angle of about 90 degrees, the disk flat, not much elevated and sloping downward around the apical margin; propodeum very short medially, triangularly enlarging towards the sides, the metapleura small. Abdomen depressed with the dorsum slightly sunken in after death, the outline as seen from above subtriangular with the basal corners and apex rounded, the length and width about equal to the thorax; fifth ventrite reaching only to the middle of the venter leaving the ovipositor free beyond this point, the sheaths shortly protruded, slender, terete and abruptly tapering at apex.

Legs of normal structure, the middle tibial spur very slender and tapering, almost as long as the first tarsal joint which is equal to the following four joints combined. Wings reaching far beyond the apex of abdomen and moderately narrow; disk moderately densely ciliated but more sparsely and coarsely in the angle between the speculum and strbmarginal vein, much of the rest of the basal area with finer and transparent cilia, the extreme base bare; speculum narrow; reaching practically to the posterior margin and separated from the hairless streak along the margin by only one row of transparent cilia, much narrowed above and falling considerably short of the venation; apex of venation not quite reaching to the middle of the wing, the submarginal vein somewhat enlarged before its apex although not so distinctly as in diaspidis, the marginal vein about five times as long as thick and considerably longer than in diaspidis, the postmarginal and stigmal veins about equal, each nearly a third as long as the marginal, the stigmal triangular, narrow at the base and enlarged at apex.

Face finely reticulate, more delicately and a little more finely on the 
median ridge and changing to very closely lineolate on each side exterior to the antennal sockets and on the cheeks; vertex much more finely but more rugosely reticulate, gradually becoming almost smooth on the frons, an orbital row of very fine, shallow pin-punctures on each side of the frontovertex, and a few scattered over the frons; mesoscutum distinctly reticulate with the lines running transversely; axillae transversely lineolato-reticulate; scutellum with crowded, microscopic thimble-like punctures appearing granular at lower magnifications and opaque in most aspects, the obliquely sloping latero-apical margin smooth and highly polished; metanotum and propodeum smooth, the metapleura highly polished; mesopleura finely reticulate with the lines running mostly lengthwise; abdomen smooth and shiny, the apical tergite, however, rather rugosely reticulate except on the sides. (Diaspidis has a smoother face with the reticulations indistinct except on the facial ridge, and the thimble-like punctures of scutellum appear to be slightly coarser).

Eyes with very sparse and extremely short pile; pubescence on other parts of head also short and sparse, yellowish white in color and confined to the frontovertex and lower part of the face; that on the thorax blackish and rather sparse and short on the mesoscutum, much longer on the scutellum and more bristle-like especially towards the apex, the four scale-like bristles at the apex very narrow and all nearly equal in length (in diaspidis these bristles are comparatively wide with the anterior pair much the shorter); pubescence on the basal corners of the propodeum, the sides of the abdomen and on the protruded part of the ovipositor sparse, fine and pale-colored.

Length: ( 0.80 to) 1.03 ; width of vertex at the anterior ocellus: 0.10 ; width of mesoscutum: 0.433 ; length of fore-wing: 1.03 ; width of forewing: 0.436 ; length of protruded part of ovipositor: $0.1 \mathrm{I} 3 \mathrm{~mm}$.

General color metallic bluish black, the luster of head bluish, becoming purplish on the sides of the face and greenish on the facial ridge; luster of thorax mostly bluish or bluish-green and slightly purplish in part, the scutellum usually appearing dull black, its apex, however, the lateral margins as well as the metapleura brilliant metallic green and brassy; abdomen brilliant metallic green on the first tergite and lateral margins near apex, the remainder with various metallic reflections but usually dark purplish and bronzy. Basal half of the scape, pedicel except at apex, first two funcle joints and club black; the rest of scape, apical third of pedicel and last two funicle joints yellow. Legs mostly yellowish white with the front and hind coxae and femora except at base black, the middle femora with a narrow black ring just before the apex and rather indistinct on the under side; front tibiae with a black ring reaching about to the middle, the base narrowly white; a similar ring on the middle tibiae only slightly wider than the preceding white base and falling considerably short of the middle; hind tibiae with a broad black ring reaching a little beyond the middle and leaving the base narrowly white; the tarsi slightly more yellowish 
beneath, and the tip of the last joint blackish. Wings hyaline, the veins yellowish but the stigmal and the submarginal except at base and apex are much more transparent than the rest of the venation.

Male: Not known.

Described from four females (type and paratypes) collected at Nuuanu Pali, Oahu, Oct. 19, 1919 (W. M. Giffard).

This species is very similar to Plagiomerus diaspidis Crawford but can be distinguished by the nearly bare eyes, the narrower wings and frontovertex and by the slender lamelliform bristles on the scutellum. The coloration is similar but the black band on the middle femora is much narrower.

The host of hospes is unknown but judging from the habits of other members of the genus it should prove to be a Diaspine scale. The species is no doubt immigrant and presumably came from some part of America as the genus has not been recognized hitherto outside of North America. As no males of Plagiomerus have been discovered it is becoming apparent that the species are thelyotokous and maleless under ordinary circumstances.

\section{Anabrolepis $\mathrm{n} . \mathrm{g}$.}

Female: Head as seen from the side distinctly triangular and as seen from above almost perfectly semicircular in outline; the dorsal surface much flattened especially in the longitudinal axis, its plane forming an acute angle with the strongly obliquely inclined ventroanterior surface although the angulation is somewhat rounded off; eyes and frons not entirely dorsal but continued distinctly beyond the angulation on to the ventro-anterior surface; anterior orbits of the eyes with a distinct but narrow furrow continuous across the face between the eyes, thus marking the anterior boundary of the frons and lined throughout with silvery white, short and recumbent hairs. Antennae rather short and stout, the scape compressed and a little widened towards the apex, the pedicel rather short and thick, the funicle six-jointed with the joints mostly transverse, the club slightly longer than the funicle.

Thorax depressed, the mesoscutum being very flat; scutellum a little wider than long, at apex nearly rectangular and without any bristles. Abdomen triangular as seen from above, a little narrower than the thorax and about as long, the ovipositor shortly protruded. Wings nar- 
row, marked with a longitudinal fuscous band and several rays along the margin alternating with hyaline spots; marginal vein stout and about four times as long as thick although much obscured by numerous strong bristles, the stigmal vein about one-half as long, the postmarginal short and spur-like.

Male: Not known.

Genotype: Anabrolepis extranea n. sp.

This genus is closely allied to Habrolepis Förster and Adelencyrtus Ashmead, but is distinguished from the former by the absence of lamelliform bristles on either the verticooccipital margin or apex of the scutellum and by the different wing pattern, and from Adelencyrtus by the Alattened dorsal surface of the head, which is more acutely angled with the anterior surface, and by the fuscous rays on the wings. The European species, Encyrtus zetterstedtii, hitherto placed in Habrolepis no doubt belongs here and may be known as Anabrolepis zetterstedtii (Westwood).

The following analysis of the described Habrolepis-like genera while not entirely satisfactory, because prepared in part from descriptions only, may help the student to distinguish these interesting forms. It is rather significant that of the seven genera three are represented in Hawaii by an immigrant species. This relatively high proportion is probably due to the fact that the species are parasitic in common and frequently transported scale-insects, and secondly that thelyotokous reproduction is apparently the rule in the group and thus their establishment in a new locality is made comparatively easy.

Characters common to the group of Habrolepis-like genera : Head triangular in side view with the face strongly reflexed, the planes of the face and frons meeting in a more or less acute angle; antennae simple and usually moderately clavate, the funicle with four or six joints; mandibles much flattened or not curved inward at apex, the ventral margin with a strong preapical spine, the apex not greatly narrower than the base, and armed with an acute ventral tooth and an obliquely inclined inner margin variously subdivided into two to four additional teeth; the vertico-occipital margin ornamentcd in three genera with a pair of lamelliform bristles, the scutellum in four genera with one or two pairs of similar but ustally wider bristles. 
Females.*

I. Funicle six-jointed

Funicle four-jointed.

Scutellum with one or two pairs of lamelliform bristles at apex_-_2

Apical bristles of scutellum not modified.

Marginal vein thrice as long as wide, the stigmal and portmarginal subequal and about two-thirds as long as the marginal; mandibles with small, subacute teeth; wings hyaline with a fuscous area beneath the apex of venation...-.-.---_-Parahomalopoda Girault

2. Dorsal surface of the head flattened or only slightly convex from side to side; the vertico-occipital margin with a pair of slender lamelliform bristles, the apex of scutellum with one pair of wider bristles; wings with fuscous rays from a median longitudinal band

Dorsal surface of head convex with the eyes almost wholly dorsal; the face inflexed but meeting the plane of the frons in a broad curve, the scrobal impression triangular limited above by a semicircular rounded ridge just in front of the eyes; vertico-occipital margin rather acute and with a pair of simple bristles, the scutellum with two pairs of lamelliform bristles; wings hyaline-_Plagiomerus Crawford

3. Antennae slender, the scape not expanded beneath, the funicle joints

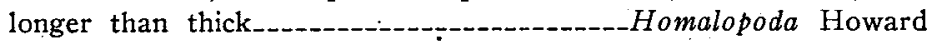

Antennae short and stout, the scape dilated towards the apex, the funicle joints much wider than long and subcompressed.

Pseudhomalopoda Girault

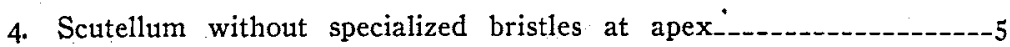

Scutellum with a pair of broad lamelliform bristles at apex.

Face very strongly reflexed, vertico-occipital margin with a pair of lamelliform bristles; antennae slender or but weakly clavate; wings fuscous with a pair of hyaline spots beyond the venation and a subapical, hyaline cross-band.-----_-_Habrolepis Foerster

5. Dorsal surface of the head flat or only slightly rounded from side to side, and semicircular in outline, the anterior surface sharply reflexed although the angulation is somewhat rounded off; eyes and frons not entirely dorsal but distinctly reflexed on to the anterior surface; anterior orbits of the eyes with a silvery pubescent, narrow furrow continuous across the face; wings with fuscous rays

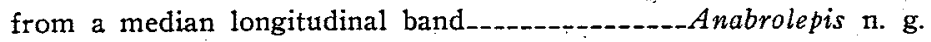

*The male has been described only for genus Habrolepis. It has two short ring-like funicle joints and an elongate cylindrical club. 
Dorsal surface of the head strongly convex and broadly cresentic in outline, the anterior surface less sharply reflexed and the angulation strongly rounded off in a broad curve; anterior orbits of the. eyes not furrowed and without a silvery pubescent line; wings hyaline or faintly fuscous with two triangular hyaline areas forming a cross-band just beyond the venation--Adelencyrtus Ashmead

Anabrolepis extranea n. sp. Figs. 22, 23.

Female: In side view of the head the facial side of the triangular outline is the longest, the dorsal and occipital sides nearly equal and forming a right angle; in frontal view the head is much wider than long, the outline of the eyes and frons forming a semicircle; occiput wider than long, not much concave, the neck inserted above the center; eyes triangular, the inner side slightly longer than the posterior, the anterior side still longer and, on the ventro-anterior surface of head; frontovertex considerably widening posteriorly and nearly twice as long as the

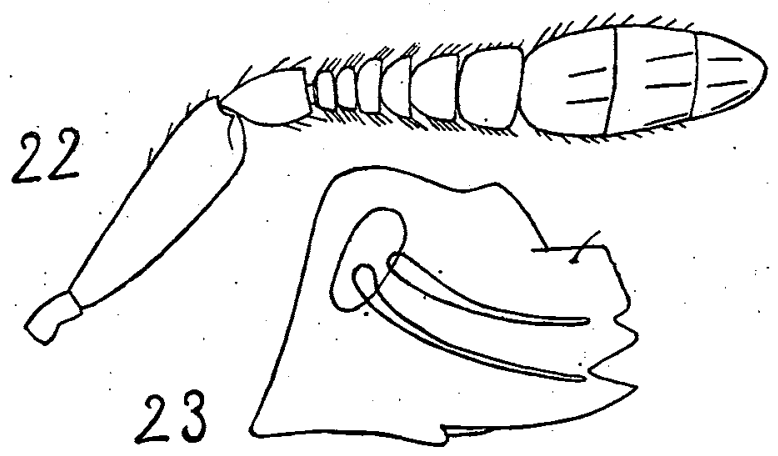

Figs. 22 and 23. Anabrolepis extranea, female antenna and mandible.

posterior width when the anterior, reflexed part of frons is counted in, the occipital margin rather acute and without bristles; ocelli arranged in a small equilateral triangle placed in the middle of the dorsal part of the frontovertex, the anterior ocellus considerably in front of the middle, the posterior pair a little behind the middle, about one-half their own diameter from the eye-margin and very remote from the occipital margin; cheeks as long as the posterior margin of the eyes and arcuately converging towards the moderately wide mouth; face wider than long, flattened and impressed with a median scrobal depression, divided by a short median rounded ridge and bounded above by .a rather broad convex space which forms a broad curve or semicircle between the depression and the eyes, the grooved pubescent line at the orbits also in the form of a semicircle, the oral margin with a broad, deep median sinus. Antennae inserted rather far apart, the space between the sockets equaling the width of the frons, and rather far above the oral margin or just below a line drawn between the lower corners of 
the eyes, with upper ends of the sockets almost touching this line; scape subcompressed, wider towards the apex or clavate in outline as seen from the side, and rather short or barely reaching to the plane of the frontovertex; pedicel about one-half longer than thick, much thicker at the apex than the following joint and a little longer than the first three funicle joints combined; flagellum short, distinctly but not greatly clavate; first four funicle joints all short, transverse and about equal in length, the last two funicle joints twice as long as the preceding joints, the fifth about as long as its apical width, the sixth a little wider than long; club narrowly ovate, rounded at apex, considerably wider and a little longer than the funicle, its basal joint somewhat the longest. Mandibles with a sharp spine on the ventral margin, the apex broad, with two strong actute, ventral teeth and a broad inner truncate margin. Maxillary palpi slender, moderately long, the basal joint a little longer than the second or third which are about equal, the fourth joint as long as the first two combined; labial palpi short and stout, the apical joint slightly longer than the basal and rounded at apex.

Thorax depressed, its depth hardly greater than one half the width, and about one half longer again than wide; pronotum deeply arcuate and narrow; mesoscutum very flat, about one half wider again than long, its posterior margin slightly angulate at the middle; axillae short, considerably over twice as wide as long, and meeting at their tips; scutellum a little wider than long, about rectangular at apex, the disk nearly flat, not greatly elevated and abruptly sloping downward along the lateral margins; propodeum very short medially but triangularly enlarging towards the sides, the metapleura small and narrow but reaching to the hind coxae. Dorsum of abdomen moderately sunken in, the venter depressed with the fifth ventrite reaching abuut to the middle and leaving the ovipositor free; protruded part of the ovipositor sheaths terete; vibrissal plates situated on the lateral margins of the dorsum half way between the base and the middle, the vibrissae falling considerably short of the apex.

Legs normal, the tarsi slender and not thickened at base, the first joint of the middle pair as long as the four following joints combined and a little longer than the slender tibial spur. Wings narrow, reaching considerably beyond the apex of the abdomen; venation reaching to the middle of the disk; submarginal vein somewhat enlarged and slightly broken at a point one third of its length from the distal end, marginal vein stout and about four times longer than thick, stigmal vein about one half as long, narrow at base and triangularly enlarged at apex, the postmarginal short and spurlike; speculum narrow and of equal width throughout, falling somewhat short of the stigmal vein but extending to the bare area along the posterior margin of the wing, and interrupted neat its lower end by two stout bristles; marginal cilia rather long, the discal cilia extremely various and helping to form the fuscous rays and band, those on the base of the disk before the specu- 
lum in the form of stout, tapering moderately long bristies with the one contiguous to the thickened part of the submarginal vein about twice as long as all the rest; those on the darkest fuscous areas beyond the speculum similar along the anterior margin of the disk but becoming somewhat finer on the median band and along the posterior margin, and interspersed throughout in the fuscous areas 'with much shorter, blunt and flattened bristles; cilia of the clear areas in part extremely fine and transparent and partly black and somewhat coarser, these dark cilia being distributed over the whole of the subapical clear spot on the posterior margin, or the inner half of the corresponding spot on the anterior margin, and along the inner margins of the median pair of clear spots, covering the inner third of the anterior one of this pair; bristles. on the submarginal vein pale colored, very slender and rather long; those on the marginal vein much shorter and stouter, being flattened and spear-shaped.

Face and cheeks with a fine delicate reticulation more evident on the sloping dorsal sides of the scrobal impression; mesoscutum much more distinctly and somewhat more coarsely reticulate; mesopleura extremely finely reticulate and nearly opaque; axillae finely, closely and transversely lineolate; frontovertex with crowded thimble-like punctures, considerably coarser than those on the scutellum of Plagiomerus yet very fine although not producing an opaque effect, and becoming obsolete anteriorly on the reflexed part of the frons; the latter with two distinct pinpunctures arranged in a transverse line at the angulation and another pair just posteriorly on the dorsal part of the frons but considerably obscured by being located at the edge of the thimble-punctured area; scutellum with similar and a little coarser thimble-punctures on the disk but becoming smooth and polished on the sloping sides and more narrowly at apex; metanotum and propodeum rather dull but without evident sculpture; abdomen mostly smooth and polished but becoming finely reticulate on the last tergite except at the sides.

Pubescence throughout very sparse and inconspicuous; the eyes bare, the other parts of the head nearly bare except for the narrow, semicircular orbital line of silvery white, recumbent hairs bounding the dorsal limits of the face; mesoscutum with sparse, fine, bristle-like and blackish hairs seriately arranged; scutellum with about six bristle-like hairs towards the base, somewhat longer than those on the mesoscutum, and with apparently no bristles at all at apex; apex of abdomen and protruded part of ovipositor with short, delicate, pale-colored pubescence.

Length: 1.07; length of head: 0.307 : width of head: 0.356 ; width of vertex at the posterior ocelli; 0.106 ; width of mesoscutum: 0.362 ; length of fore-wing: 0.912 ; width of fore-wing: 0.372 ; length of protruded part of ovipositor: $0.134 \mathrm{~mm}$.

Head and notum of thorax metallic green, the sloping sides of the scrobal impression with a purplish luster, the reflexed part of the frons bluish green; mesoscutum with more brilliant brassy and golder reflections, the underparts of the thorax black and but slightly shiny; 
abdomen metallic blue with a moderately strong luster, the sunken in area of dorsum more blackish, the ovipositor sheaths black, the spicula yellow. Antennae black, the funicle and the club somewhat more brownish, the sixth funicle joint yellow, the club slightly yellowish towards the apex. Front legs brown, with the base of the femora and the tarsi yellowish, the apical half of the tibiae yellow; middle and hind legs black, with the apical half of the middle tibia, apex of hind tibiae and both pair of tarsi, except apex of the last joint, yellow.

Fore-wings marked with fuscous rays from a longitudinal band arising from the integumentary pigment and from the dark ciliation as follows: A large quadrate fuscous area beneath the venation from the break in the submarginal to the apex of the stigmal vein enclosing a small hyaline spot between the speculum and the apical part of the submarginal vein; the first two rays on the anterior margin produced by this hyaline spot and located respectively at the break in the submarginal, and beneath the marginal and stigmal veins; the quadrate area further enclosing a central hyaline spot beneath and beyond the speculum, but the posterior margin of the disk remaining dark so that the rays on the margin at this point are not differentiated; the fuscous area continued beyond the venation as a broad median longitudinal band constricted before the apex and then triangularly enlarged at apex; the band sending out two rays above, the third and fourth on the anterior margin, one just before the constriction, the other at the apex and continuous with the triangular enlargement; the band further emitting one ray, which is narrowed at its base, just before the constriction towards the posterior margin, but the apical ray on this margin is not differentiated from the triangular enlargement of the band; the four rays on the anterior margin much darker than the rest of the fuscous area or nearly black, the first one narrowest, the others increasing gradually in width from the second to the fourth; the first pair of hyaline spots beyond the venation quadrate, the one on the anterior margin nearly square, the other a little longer than wide; the second or subapical pair of hyaline spots both wider than long; most of the submarginal vein brownish yellow, its apical part and the stigmal vein nearly hyaline, the marginal vein brown. Hind-wings entirely hyaline.

Described from 1 female (type) collected on the Manoa Cliffs .Trail, Tantalus, Oahu, Oct. 26, 1919 (W. M. Giffard). This certainly must be an immigrant species but it is not yet apparent from what part of the world it was derived, although an Oriental origin is suspected. 
NOTHS AND EXHIBITIONS.

Fig Wasps.-Mr. Ehrhorn exhibited a Philippine fig containing galls from which fig wasps had been dissected. The latter were also exhibited.

Anomala flavilabris.-Mr. Ehrhorn exhibited a specimen of this beetle killed by fungus. It had been sent from Japan by Mr. Langford, who wrote that thousands of the beetles were found dead on the ground in a locality near Tokyo. Mr. Ehrhorn stated that the pathologists of the Experiment Station, H. S. P. A., were attempting to cultivate the fungus, and that they thought it to be the same as the fungus introduced by. Mr. Muir from the Philippines a few years ago.

Callithmysus koebelei.-Mr. Bridwell exhibited a specimen of this beautiful beetle, bred from mamake (Pipturus albidus), and stated that he found the larvae in considerable numbers about two months ago on the Manoa Cliffs trail. He also reported finding larvae of another species in Byronia at the same place; and additional larvae of the species in Pittosporum on the windward side of Mt. Konahuanui.

Dolichurus stantoni.-Mr. Bridwell remarked on the great decrease in roaches of the genus Phyllodromia, brought about by the recently introduced Dolichurus from the Philippines, and paralleling the case of Anomala orientalis being quickly reduced to harmless numbers by the introduction of Scolia manilae from the Philippines.

Aphis middletoni.-Mr. Timberlake identified an Aphid which Mr. Swezey had found on the roots of Coreopsis in Kaimuki, as this species and stated that he had found it also on China aster. Mr. Ehrhorn added that this species was found commonly by Mr. Marsh on asters as early as 1910, and that it caused considerable damage to the plants. 
DEFERRED BUSINESS.

The Committee on Entomological Organization submitted a report, containing recommendations to the Bishop Museum and the Committee of the National Council of Research, on entomological work in the Pacific. The report was accepted and the Secretary ordered to communicate a copy to Dr. H. E. Gregory, Director of the Bishop Museum, and to print the same in the Proceedings. The Committee was then discharged and its work transferred to the Executive Committee with the addition of J. C. Bridwell.

The President announced the appointment of Messrs. Timberlake, Pemberton and Bridwell as a Committee on Common Names of Economic Insects, Mr. Timberlake to act as chairman.

Report of the Committee on Entomological Organization.

(Submitted Dec. 9, 1919)

Biological Problems of the Hawaitan Insect Fauna.

In the recommendations made by this Committee for lines of entomological work appropriate to be carried on by the Bishop Museum, and presented to the Society for consideration at a special meeting June 17, 1919, and later transmitted to the Director of the Museum, one topic was designated, "Biological Problems," in connection with the endemic insect fauna, without giving detailed statement of such problems. The Committee now presents a detailed outline of certain lines of work open for research investigations with the endemic Hawaiian insect fauna.

\section{Life Histories in General.}

Much remains to be done in working out life histories and other habits in all the Orders of insects; and the discovery of their food plants and host relations, or other food habits. 